Psychopharmacology 62, 207-210 (1979)

Psychopharmacology

C by Springer-Verlag 1979

\title{
Naloxone Enhancement of DMT and LSD-25 Induced Suppression of Food-Rewarded Bar Pressing Behavior in the Rat
}

\author{
Diane Ruffing, Beverly Kovacic, Sandra Demetriou, and Edward F. Domino \\ Department of Pharmacology, Lafayette Clinic, 951 E. Lafayette, Detroit, Michigan 48207, U.S.A., and \\ The University of Michigan, Ann Arbor, Michigan 48109, U.S.A.
}

\begin{abstract}
The narcotic antagonist naloxone was tested to determine its possible interaction with $\mathrm{N}, \mathrm{N}-$ dimethyltryptamine (DMT) and lysergic acid diethylamide-25 (LSD) in adult male Holtzman rats trained to press a bar on a fixed-ratio four schedule $\left(\mathrm{FR}_{4}\right)$, i.e., every fourth press earned a reward of $0.01 \mathrm{ml}$ sugar sweetened milk. LSD $(0.1 \mathrm{mg} / \mathrm{kg})$ or increasing doses of DMT $(1.0,3.2$, and $10.0 \mathrm{mg} / \mathrm{kg})$ were administered i.p. to disrupt food-rewarded fixed ratio bar pressing in a dose related fashion. Pretreatment $(5-10 \mathrm{~min})$ with behaviorally ineffective doses of naloxone $(1.0-5.6 \mathrm{mg} / \mathrm{kg})$ dramatically enhanced the effects of DMT and LSD. The content of DMT in the brain and liver of rats injected with DMT alone $(10 \mathrm{mg} / \mathrm{kg})$ and with a $5 \mathrm{~min}$ pretreatment of naloxone $(3.2 \mathrm{mg} / \mathrm{kg})$ was determined by radiochemical analysis at 30 and $90 \mathrm{~min}$ after ${ }^{14} \mathrm{C}$-DMT injection. There was no significant difference for either brain or liver ${ }^{14} \mathrm{C}$-DMT levels when control DMT rats were compared with the naloxone pretreated rats. These results seem to rule out interference by naloxone with the metabolism of DMT as a mechanism of the observed behavioral potentiation.
\end{abstract}

Key words: Naloxone - Potentiation - DMT - LSD - $\mathrm{FR}_{4}$ operant behavior - Rat - Brain - Liver

Recently, Fertziger and Fischer (1977) described a complex interaction between naloxone and LSD in the rat. When given as a post-treatment, naloxone antagonized LSD-induced catalepsy; but when given as a pretreatment, it shortened LSD-induced excitation and enhanced the catalepsy. One possible explanation of the prolonged catalepsy was an interference with the metabolism of LSD. Since we have had considerable experience studying the effects of DMT and LSD on
$\mathrm{FR}_{4}$ behavior in the rat, we decided to investigate and extend the findings of Fertziger and Fischer (1977).

\section{Materials and Methods}

Subjects. Male Holtzman rats at least 90 days old were maintained at approximately $70 \%$ of their expected free feeding weight and housed individually in a constant temperature and humidity facility.

Procedure. Rats were trained to press a bar for an hour daily using $0.01 \mathrm{ml}$ of sugar sweetened, water diluted evaporated milk as positive reinforcement. The milk was prepared by combining $400 \mathrm{ml}$ of evaporated milk with $400 \mathrm{ml}$ tap water and $60 \mathrm{~g}$ of granulated sugar. Daily experiments were conducted in a darkened, isolated room using Lehigh Valley Electronics rodent operant test cages model 143-21. The daily bar-pressing schedule was fixed-ratio four $\left(\mathrm{FR}_{4}\right)$ i.e., every fourth bar press earned a reward. Cumulative recorders automatically recorded bar presses, reinforcements, and any disruption of normal bar pressing. Upon stabilization of $\mathrm{FR}_{4}$ behavior, each rat was then subjected to a daily schedule of an hour of bar pressing for at least 5 days prior to any injections. The training and testing procedures were similar to those previously described by Kovacic and Domino (1976). Animals used in the study were drug free for a minimum of 10 days prior to the experiment and had no past drug history of long-acting compounds. Rats served as their own controls to compare the effect of a hallucinogen with and without naloxone pretreatment. All rats were scheduled in randomly assigned groups. Drug-free intervals of 1 week were observed for all pretreatment groups. Because of the short action of DMT, less than a full week was accepted as a drug-free interval for DMT control groups. Doses of DMT (1.0, 3.2, and $10.0 \mathrm{mg} / \mathrm{kg})$ or LSD $(0.1 \mathrm{mg} / \mathrm{kg})$ were administered i.p. to disrupt food-rewarded fixed ratio bar pressing in a dose related fashion. Log doses of naloxone $(1.0,2.4,3.2$, and $5.6 \mathrm{mg} / \mathrm{kg})$, which had demonstrated no effect on normal bar pressing behavior for periods up to $60 \mathrm{~min}$, were used as pretreatment doses. No $0.9 \% \mathrm{NaCl}$ pretreatments were used for control hallucinogen reactions since it had previously been demonstrated that saline pretreatment does not alter reactions to DMT or LSD (Kovacic and Domino, 1976; Kovacic et al., 1978).

In the control procedure, rats were placed in an operant chamber for $15 \mathrm{~min}$ of bar pressing, injected with the hallucinogen (i.p.), and returned immediately to the operant chamber until the rat recovered and bar pressed at a rate of $90 \%$ of control for a $60 \mathrm{~min}$ period. Animals were observed and behavior was noted for the duration of the drug effect. 
For the pretreatment procedure, rats were pretreated with naloxone (i.p.) and immediately placed in the operant chamber to bar press for 5-10 min, injected with the hallucinogen (i.p.), and returned immediately to the operant chamber until the rat recovered and bar pressed steadily for $60 \mathrm{~min}$ or more. Animals were observed and behavior was noted for the duration of the drug effect.

Data Analysis. The duration of the drug effect was measured by the horizontal line generated by the cumulative recorder during the cessation of normal bar pressing. Since both onset and recovery of DMT and LSD effects are sudden and complete, the duration of the drug effect could easily be calculated from the length of the horizontal segment. To statistically analyze this data, two-tailed Student $t$-tests were calculated according to Snedecor (1956) using the value of $P$ $<0.05$ as significant.

Drugs. Naloxone hydrochloride was administered in $0.9 \% \mathrm{NaCl}$; concentrations refer to free base. DMT doses refer to free base; solutions were prepared by dissolving the free base in $1 \mathrm{~N} \mathrm{HCl}$, adding $0.9 \% \mathrm{NaCl}$, and adjusting the $\mathrm{pH}$ with $0.1 \mathrm{~N} \mathrm{NaOH}$, rendering the final volume at a $\mathrm{pH}$ of $4.5-6.0$. Doses of LSD refer to LSD-25 salt. Naloxone was obtained courtesy of the Endo Laboratories. DMT was obtained from the Sigma Chemical Company. LSD (Delysid) substance was obtained from the National Institute on Drug Abuse.

Chemical Methods. Male Holtzman rats, unfasted, weighing approximately $500 \mathrm{~g}$ were used for chemical analysis. Pretreated rats were injected with naloxone $3.2 \mathrm{mg} / \mathrm{kg}$ (i.p.) $5 \mathrm{~min}$ prior to ${ }^{14} \mathrm{C}$-DMT $10 \mathrm{mg} / 3 \mu \mathrm{Ci} / \mathrm{kg}$ (i.p.). Control rats received only ${ }^{14} \mathrm{C}-\mathrm{DMT}$ $10 \mathrm{mg} / 3 \mu \mathrm{Ci} / \mathrm{kg}$ (i.p.). The rats were sacrificed by guillotine at $30 \mathrm{~min}$ and $90 \mathrm{~min}$ after the ${ }^{14} \mathrm{C}$-DMT injection. The entire brain and approximately $2 \mathrm{~g}$ of liver from each rat were immediately removed and homogenized in ice cold $1 \mathrm{~N} \mathrm{HCl}$. The homogenates were assayed for total radioactivity, total acidic metabolites, and DMT (as previously described in Lu et al., 1974, 1978).

$\mathrm{N}, \mathrm{N}$,-Dimethyltryptamine side chain-1- ${ }^{14} \mathrm{C}$-hydrogen oxalate was purchased from New England Nuclear, Boston, MA. The ${ }^{14} \mathrm{C}$ DMT $10 \mathrm{mg} / 3 \mu \mathrm{Ci} / \mathrm{ml}$ solution was prepared by mixing nonradioactive DMT with radioactive DMT.

\section{Results}

Gross behavioral reactions to DMT and LSD alone and with pretreatment of naloxone were uniform despite the prolongation of these reactions by naloxone pretreatment. Approximately $1-5 \mathrm{~min}$ following an injection of DMT or LSD (with or without naloxone pretreatment) the rats would abruptly stop bar pressing and display characteristic behavioral reactions, such as mainly lying quiet in a flattened position, twitching, flattening and extension of the hind limbs, crawling with jerky movements, occasional Straub tail, arching, and occasional repetitious head movements. The duration of bar pressing disruption in DMT and LSD control groups and also in naloxone-pretreated groups is dose related as shown in Figs. 1 and 2. Enhancement of behavioral suppression by $\operatorname{LSD}(0.1 \mathrm{mg} / \mathrm{kg}$, i.p. $)$ and DMT $(10.0 \mathrm{mg} / \mathrm{kg}$, i.p. $)$ is shown in Fig. 1 with pretreatment of $\log$ doses of naloxone $(1.0,2.4,3.2$, and $5.6 \mathrm{mg} / \mathrm{kg}$, i.p.) $5-10 \mathrm{~min}$ prior to LSD or DMT. Despite the prolongation of DMT and LSD reactions by naloxone in all groups, bar pressing began abruptly and continued at the pre-injection rate at the end of

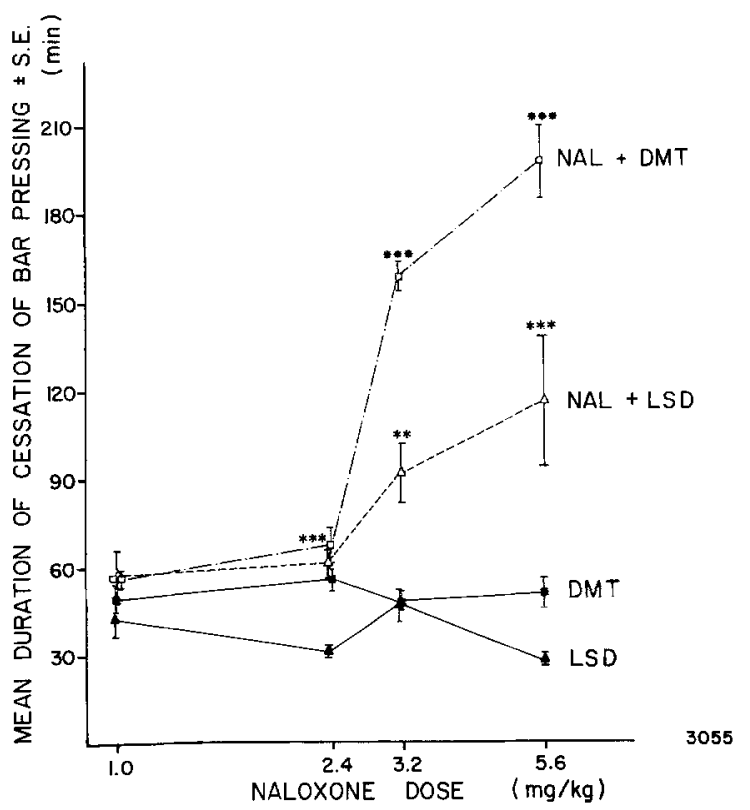

Fig. 1. Dose effect of naloxone enhancement of LSD and DMT suppression of $\mathrm{FR}_{4}$ behavior in the rat. Increasing doses of naloxone $(N A L)$ were given to each group of $5-8$ animals per point 5 to $10 \mathrm{~min}$ prior to DMT or LSD. Control animals received either DMT or LSD alone. A fixed dose of $0.1 \mathrm{mg} / \mathrm{kg}$ of LSD or $10 \mathrm{mg} / \mathrm{kg}$ of DMT was used for both groups of animals. Each animal given naloxone plus the hallucinogen was also given at a different time the hallucinogen alone. Although the different groups show some variability to DMT and LSD alone, naloxone significantly enhanced the suppressant effects. In this and subsequent figure ${ }^{*} P<0.05, * * P<0.01$ and $* * * P$ $<0.001$ paired comparison $t$-est. All injections were made i.p.

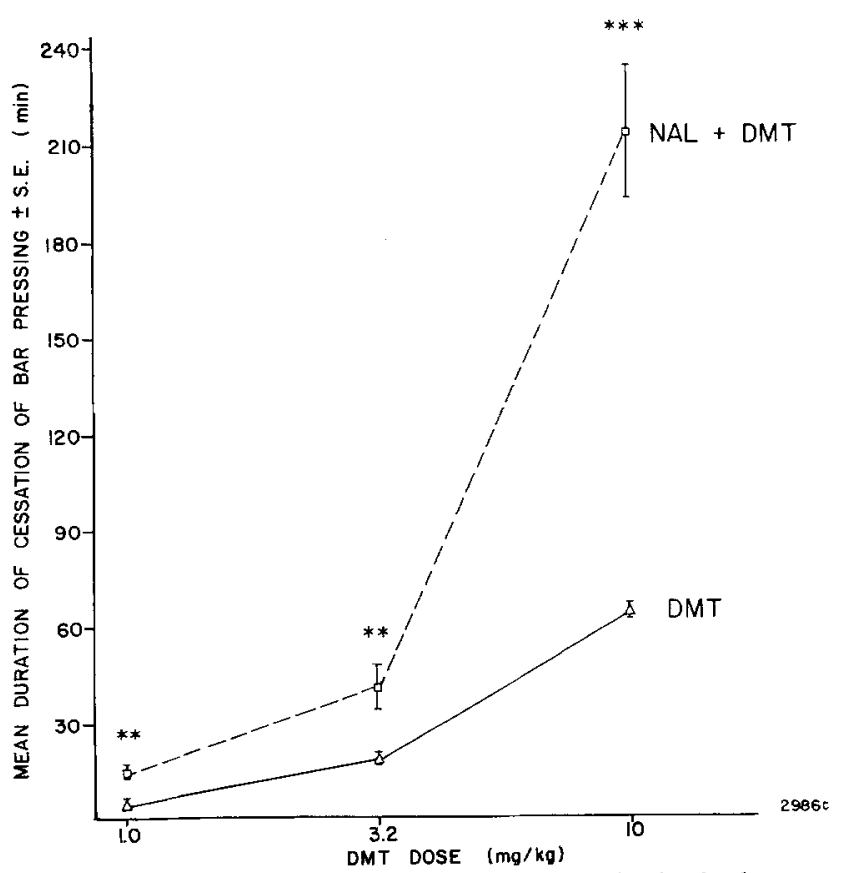

Fig. 2. Dose effect of DMT suppression of $\mathrm{FR}_{4}$ behavior in the rat with and without naloxone pretreatment. Each rat served as his own control. Each point represents the mean suppression time for groups of six animals given naloxone in a dose of $3.2 \mathrm{mg} / \mathrm{kg} 5 \mathrm{~min}$ prior to DMT or DMT alone. A dose of $3.2 \mathrm{mg} / \mathrm{kg}$ of naloxone does not affect $\mathrm{FR}_{4}$ bar pressing 
Fig. 3

Histogram comparison of radioactivity levels in the brain and liver of ${ }^{14} \mathrm{C}$-DMT $(10.0 \mathrm{mg} / \mathrm{kg})$ control groups and naloxone pretreated groups $\left(3.2 \mathrm{mg} / \mathrm{kg} 5 \mathrm{~min}\right.$ prior to $\left.{ }^{14} \mathrm{C}-\mathrm{DMT}\right)$.

Untrained rats (8 per group) were given either naloxone plus DMT or DMT alone under an identical schedule as trained animals. The animals were killed 30 and $90 \mathrm{~min}$ after ${ }^{14} \mathrm{C}$ DMT. Their brains and livers were removed and assayed for ${ }^{14} \mathrm{C}$-DMT and ${ }^{14} \mathrm{C}$-acidic content. No differences were noted

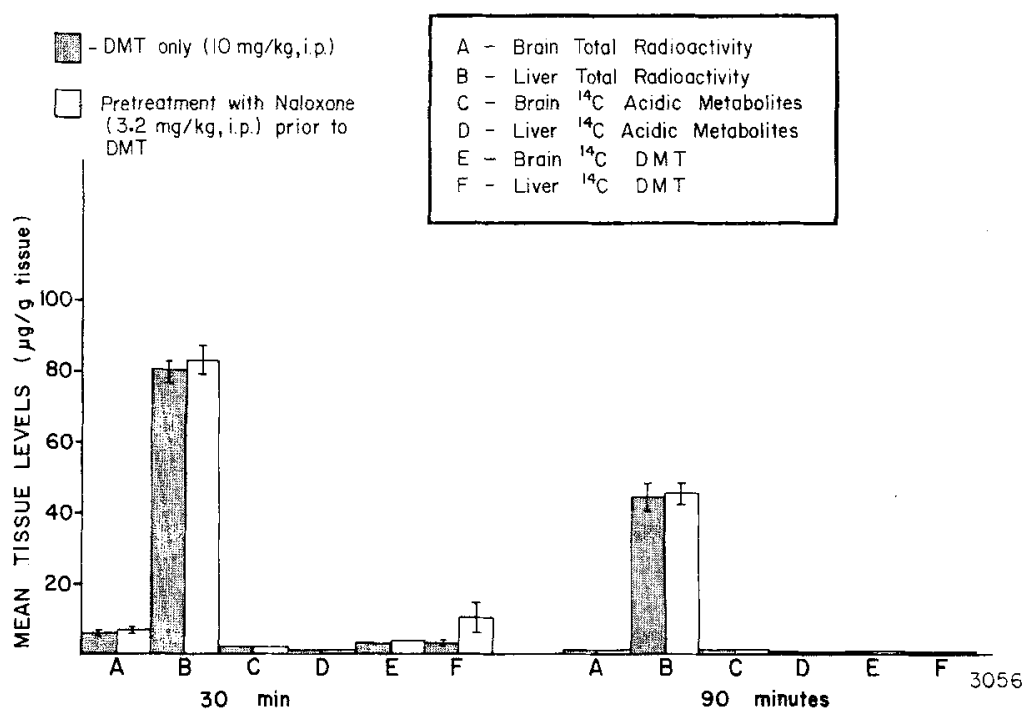

each drug reaction. Enhancement of DMT-induced behavioral suppression (doses 1.0, 3.2, and $10.0 \mathrm{mg} / \mathrm{kg}$, i.p.) is shown in Fig. 2 with pretreatment of naloxone $(3.2 \mathrm{mg} / \mathrm{kg}$, i.p.) $5 \mathrm{~min}$ prior to DMT.

To determine whether naloxone was interferring with the metabolism of DMT, rat brain and liver were assayed for ${ }^{14} \mathrm{C}$-DMT. When control untrained groups of rats were compared to naloxone pretreated groups, analyzed by group comparison Student $t$-tests, no significant differences were found in brain or liver DMT or acid metabolite content as shown in Fig. 3.

\section{Discussion}

$\mathrm{N}, \mathrm{N}$-dimethyltryptamine (DMT) and lysergic acid diethylamide-25 (LSD) are substances used as models for the study of psychosis as they mimic schizophrenia in many aspects (Gillin et al., 1976; Fischer, 1974; Appel and Freedman, 1965; Wyatt et al., 1973, 1974; Jacobsen, 1963; Domino, 1975). DMT has been postulated and sometimes identified as being an endogenous substance (Lu et al., 1974; Corbett et al., 1978; Appel and Freedman, 1965; Narasimhachari et al., 1971; Vogel and Evans, 1977; Oon et al., 1977; Lord et al., 1977; Bloom et al., 1976; Marx, 1976; Angrist et al., 1976). Similarly, an endogenous ligand of a putative LSD-serotonin receptor has been described in the cerebrospinal fluid of unmedicated psychotic patients (Mehl et al., 1977). Naloxone has been reported to reduce the auditory hallucinations in some schizophrenic patients (Gunne et al., 1977; Terenius et al., 1977; Watson et al., 1978) but has also been ineffective in other cases (Gitlin and Rosenblatt, 1978; Janowsky et al., 1977a, b; Davis et al., 1977). These and other reports of enhanced opiate-like material in the cerebrospinal fluid have raised speculations regarding an abnormal endogenous opiate associated with mental disease.

Fertziger and Fischer (1977) have described that LSD induced in rats a diphasic reaction consisting of an initial excitatory phase and a prolonged catalepsy phase. Naloxone given after LSD antagonized the cataleptic phase, but when given as a pretreatment shortened the excitation and prolonged the cataleptic response. Their findings, as well as those of Belluzzi et al. (1976), that naloxone can antagonize enkephalininduced analgesia, suggests an interaction among naloxone, LSD, and endogenous opiates. Our data, demonstrating that ${ }^{14} \mathrm{C}$-DMT levels are not altered by naloxone, strengthen this possibility. Nevertheless, other possibilities which do not implicate endogenous opiates must be excluded prior to considering this hypothesis seriously. At least in the case of DMT, it appears that altered DMT levels are not involved in the naloxone enhancement of DMT behavioral depression. It is to be emphasized that the dose of naloxone used which enhances the actions of both DMT and LSD alone does not alter the $\mathrm{FR}_{4}$ behavior, although much larger doses of naloxone alone are disrupting.

Acknowledgements. The naloxone hydrochloride was a gift from the Endo Laboratories and the LSD-25 was a gift from the National Institute on Drug Abuse. We gratefully acknowledge the assistance of the Lafayette Clinic Electronics Laboratory.

\section{References}

Angrist, B., Gershon, S., Sathananthan, G., Walker, R. W., LopezRamos, B., Mandel, L., Van den Heuvel, W.: Dimethyltryptamine levels in blood of schizophrenic patients and control subjects. Psychopharmacology 47, 29-32 (1976)

Appel, J. B., Freedman, D. X. : The relative potencies of psychotomimetic drugs. Life Sci. 4, $2181-2186$ (1965) 
Belluzzi, J. D., Grant, N., Garsky, V., Sarantakis, D., Wise, C., Stein, L.: Analgesia induced in vivo by central administration of enkephalin in rat. Nature 260, 625-626 (1976)

Bloom, F., Segal, D., Ling, N., Guillemin, R.: Endorphins: Profound behavioral effects in rats suggest new etiological factors in mental illness. Science 194, 630-632 (1976)

Corbett, L., Christian, S. T., Morin, R. D., Benington, F., Smythies, J. R. : Hallucinogenic N-methylated indolealkylamines in cerebrospinal fluid of psychiatric and control populations. Br. J. Psychiatry 132, 139-144 (1978)

Davis, G. C., Bunney, W. E., DeFraites, E. G., Kleinman, J., Van Kammen, D., Post, R., Wyatt, R.: Intravenous naloxone administration in schizophrenia and affective ilfness. Science 197, $74-77$ (1977)

Domino, E. F. : The indole hallucinogen model: Is it worth pursuing? In: Predictability in Psychopharmacology: Preclinical and clinical correlations, A. Sudilovsky, S. Gershon, and B. Beer, eds., pp. 247-268. New York: Raven Press 1975

Fertziger, A., Fischer, R.: Interaction between narcotic antagonist (naloxone) and lysergic acid diethylamide (LSD) in the rat. Psychopharmacology 54, 313-314 (1977)

Fischer, R.: A pharmacological and conceptual reevaluation of hallucinogens. Cofinia Psychiatr. 17, 143-151 (1974)

Gillin, J. C., Kaplan, J., Stillman, R., Wyatt, R. J.: The psychedelic model of schizophrenia: The case of $\mathrm{N}, \mathrm{N}$-dimethyltryptamine. Am. J. Psychiatry 133, 203-208 (1976)

Gitlin, M., Rosenblatt, M.: Possible withdrawal from endogenous opiates in schizophrenics. Am. J. Psychiatry 135, 377-379 (1978)

Gunne, L., Lindström, L., Terenius, L. : Naloxone-induced reversal of schizophrenic hallucinations. J. Neural. Transm. 40, 13-19 (1977)

Jacobsen, E.: The clinical pharmacology of the hallucinogens. Clin. Pharmacol. Ther. 4, 480-503 (1963)

Janowsky, D., Segal, D. S., Bloom, F., Abrams, A., Guillemin, R.: Lack of effect naloxone on schizophrenic symptoms. Am. J. Psychiatry 134, 926-928 (1977a)

Janowsky, D., Segal, D. S., Abrams, A., Bloom, F., Guillemin, R.: Negative naloxone effects in schizophrenic patients. Psychopharmacology 53, 295-297 (1977b)

Kovacic, B., Domino, E. F.: Tolerance and limited cross-tolerance to the effects of N,N-dimethyltryptamine (DMT) and lysergic acid diethylamide-25 (LSD) on food rewarded barpressing in the rat. J. Pharmacol. Exp. Ther. 197, 495-502 (1976)

Kovacic, B., Lu, L. J. Wang, Ruffing, D., Domino, E. F.: Interactions of partial LSD analogs with behavioral disrupting effects of LSD and DMT in the rat. Eur. J. Pharmacol. 47, 3744 (1978)

Lord, J. A., Waterfield, A. A., Hughes, J., Kosterlitz, H. W.: Endogenous opioid peptides: Multiple agonists and receptors. Nature 267, 495-499 (1977)

Lu, L. J., Demetriou, S. D., Domino, E. F.: Effects of various neuroleptics, phenobarbital and SKF 525-A on dimethyltryptamine content in rat brain and liver. Arch. Int. Pharmacodyn. Ther. 232, 117-133 (1978)

Lu, L. J., Wilson, A., Domino, E. F.: Correlation between brain N,Ndimethyltryptamine (DMT) levels and barpressing behavior in rats. The Pharmacologist 16, 237 (1974)

Marx, J. L.: Neurobiology: Researchers high on endogenous opiates. Science 193, $1227-1229$ (1976)

Mehl, E., Rüther, E., Redemann, J.: Endogenous ligands of a putative LSD-serotonin receptor in the cerebrospinal fluid: Higher level of LSD-displacing factors (LDF) in unmedicated psychotic patients. Psychopharmacology 54, 9-16 (1977)

Narasimhachari, N., Heller, B., Spaide, J., Haskovec, L., Meltzer, H., Strahilevitz, M., Himwich, H. E.: N,N-Dimethylated indoleamines in blood. Biol. Psychiatry 3, $21-23$ (1971)

Oon, M. C., Murray, R. M., Rodnight, R., Murphy, M. P., Birley, J. L.: Factors affecting the urinary excretion of endogenously formed dimethyltryptamine in normal human subjects. Psychopharmacology 54, 171-175 (1977)

Snedecor, G. W.: Statistical Methods, Fifth Edition. Ames: Iowa State College Press 1956

Terenius, L., Wahlström, A., Agren, H.: Naloxone (Narcon) treatment in depression: Clinical observations and effects on CSF endorphins and monoamine metabolites. Psychopharmacology 54, $31-33$ (1977)

Vogel, W. H., Evans, B. D.: Structure-activity relationships of certain hallucinogenic substances based on brain levels. Life Sci. 20, $1629-1636$ (1977)

Watson, S., Berger, P., Akil, H., Mills, M., Barchas, J. D. : Effects of naloxone on schizophrenia: Reduction in hallucinations in a subpopulation of subjects. Science 201, $73-76$ (1978)

Wyatt, R. J., Gillin, J. C., Kaplan, J., Stillman, R., Mandel, L., Ahn, H. Van den Heuvel, W. Walker, R.: N,N-Dimethyltryptamine - A possible relationship to schizophrenia. Adv. Biochem. Psychopharmacol. 11, 299-313 (1974)

Wyatt, R. J., Saavedra, J. M., Axelrod, J.: A dimethyltryptamine (DMT) forming enzyme in human blood. Am. J. Psychiatry 130, $754-760(1973)$

Received October, 1978 